\title{
The thinking and practice of Marine Ecological Conservation Red Line Delineation in China
}

\author{
Bei Zhao ${ }^{1}$, Yanrong Zhou ${ }^{1}$, Nana Liu ${ }^{1}$, Kun Yang ${ }^{1}$, and Jing $\mathrm{Li}^{1 *}$ \\ ${ }^{1}$ North China Sea Environmental Monitoring Center, State Oceanic Administration, China
}

\begin{abstract}
China has established and implemented marine ecological conservation red line (MECRL) system to strengthen the bottom line constraints and ensure ecological security. This paper introduces the concept of MECRL and the process of overall consideration of the national MECRL delineation, which is defined "spatial-division + differential control measures". The MECRL in Bohai Sea pilot and delineation of MECRL nationwide are introduced. At present, MECRL accounts for about 30 percent of the total coastal management area, providing a good institutional guarantee for protecting marine ecology and guiding the good formation of a scientific marine spatial layout in china.
\end{abstract}

\section{Introduction}

China is rich in marine resource and marine biodiversity, with a total area of 3 million square kilometers under its jurisdiction, including Bohai Sea, Yellow Sea, East China Sea and South China Sea. There are mangroves, coral reefs, coastal wetlands, seagrass beds, islands, bays, estuaries and other types of marine ecosystems across the three climatic zones of warm temperate zone, subtropical zone and tropical zone. Marine resources and marine biodiversity are very rich, providing an important guarantee for the sustainable development of coastal economy and society. However, in recent years, due to multiple factors such as coastal development, population aggregation and resource and environment pressure, a large number of Marine space resources in coastal areas have been occupied, and the pressure on Marine ecosystem has been under increasing pressure. According to the continuous monitoring results of the Bulletin on the State of China's Marine Ecology and Environment, the water quality of some marine areas in China is still not optimistic, and the function of regional marine ecosystem has been degraded. It is urgent to establish marine environmental protection policies based on regional management and by means of Ecological Conservation Red Line, guided by the concept of marine ecological civilization, aiming at harmony between human and sea, so as to safeguard the safety and health of China's Marine ecology.

\section{The concept of marine ecological conservation red line}

The concept of red line originated in urban planning, which refers to a prohibited area. The red line is legally, mandatory, and no building or structure shall exceed the building red line ${ }^{[1]}$. There is no concept of Ecological Conservation Redline abroad ${ }^{[2]}$, which is an institutional innovation in the field of ecological protection in China.

The red line was first introduced into the ecological field in 2000 when Gao Jixi put forward the red line control scheme ${ }^{[3]}$ in ecological planning in Anji, Zhejiang Province. In 2012, The State Oceanic Administration launched the delineation of MECRL in bohai sea, aiming to implement a stricter marine ecological protection system.

MECRL refers to the marine ecological space with special important ecological functions, which must be strictly protected, including extremely important ecological functions areas, sensitive and fragile ecological areas, such as biodiversity conservation, coastal ecological stability. MECRL is an important part of China's pattern of marine space development and protection, which is also an important basis for the unified implementation of marine space use control and ecological protection and restoration. China attached great importance to the establishment of ecological conservation red line system, and has put forward clear requirements for the work of ecological conservation redline in important ecological protection strategies.

In 2014, Article 29 of the Environmental Protection Law of the People's Republic of China (Revised and adopted at the eighth meeting of the Standing Committee of the 12th National People's Congress on April 24, 2014) clearly stipulates that "China set the ecological conservation red line in key ecological functional areas, sensitive areas and vulnerable areas of the ecological environment, and implement strict protection."

In 2016, the revised Marine Environmental Protection Law of the People's Republic of China incorporated MECRL system into the basic law of marine

\footnotetext{
* Corresponding author: bhjczx_lijing@ncs.mnr.gov.cn
} 
environmental protection, and MECRL was officially established at the legal level ${ }^{[4]}$.

\section{The role of marine ecological conservation red line}

MECRL with the strictest marine ecological protection system protects the national marine ecological health and ecological safety bottom line, and together with marine function zoning and marine main function zoning plans to improve the marine spatial planning system in China. Once delineated, MECRL will become an insurmountable space protection line, which will implement the strictest environmental access and control measures, and will serve as the basis for China to build a framework for marine ecological security.

Firstly, The MECRL strengthens marine ecological protection and strictly protect important areas of Marine ecological function, such as important estuaries, important coastal wetlands, mangroves, coral reefs, and seagrass beds, which effectively restore the damaged and degraded ecosystem, strengthen the protection of marine biodiversity and ensure that the ecological functions are not degraded.

Secondly, reclamation and other activities affecting the protected objects within the redline are prohibited. Through spatial constraints on the use of the sea, strict prevention and control shall be carried out at the source, so as to reduce the interference of human activities on the objects under the protection of the red line, ensure the ability to provide Marine ecosystem services in a sustainable manner, and ensure that the area of the red line is not reduced

Thirdly, from the perspective of ecosystem function, we should severely crack down on human activities that illegally damage marine ecosystem functions, strengthen marine ecological protection, renovation and restoration, maintain the marine ecological environment in the marine ecological protection red line area, restore damaged and degraded ecosystems, and manage and protect the ecological red line. Specific measures include strengthening surveillance and monitoring, strict supervision and inspection, strict responsibility assessment, carrying out early warning and prompt, and establishing law enforcement inspection, supervision and accountability mechanisms.

Fourthly, the evaluation results will be included in the assessment of marine ecological civilization construction objectives. The assessment results shall be incorporated into the natural resources balance sheet. The environmental quality and the total amount of marine natural resources within the marine ecological protection red line reflected in the balance sheet shall not show a trend of gradual decline.

\section{Basic train of thought of MECRL delineation}

\subsection{Overall consideration}

The national MECRL follows the following principles:

MECRL takes into account both conditions of natural resources, the ecological environment and geographical location, and the need for sustainable economic and social development of the country and region. On the basis of maintaining the marine ecological function and the capacity of resources and the environment, the marine ecological protection and marine environmental quality bottom line should be defined by zoning, and all kinds of activities damaging the protected objects in MECRL areas should be strictly prohibited. At the same time, the demand for sustainable development should be taken into account, so as to leave room for future marine industry and social and economic development.

According to the characteristics and protection requirements of the marine ecosystem, MECRL should be delineated, and differentiated control measures should be formulated to effectively protect the national important ecological function areas, marine ecological sensitive areas and marine ecological fragile areas.

Equal attention should be given to ecological protection and restoration. Ecologically sensitive and fragile areas and important ecosystems should be included into the category of MECRL so as to limit the expansion of industries that damage dominant ecological functions and follow the path of ecological and economic development. Ecosystems that are already damaged and need to be remedied and restored should also be included in MECRL to curb further ecological damage.

The delineation of MECRL should be effectively linked with the issued national and provincial marine function zoning, national marine major function zoning plans, national strategic planning and other sea-related zoning and planning, with the focus on marine ecological protection. The management of MECRL area should be stricter than other zoning and planning. The delineation of MECRL in cross-provincial and cross-municipal coastal waters should be coordinated and cohesive.

\subsection{Delineation path}

Domestic scholars have studied the delineation of MECRL from aspects of the capacity of marine resources and environment, marine spatial planning technology, etc. ${ }^{[5-7]}$. MECRL system currently implemented in China takes into account the differences in the spatial distribution of marine ecological functions, regional marine development and utilization, etc. By delineating MECRL, the behaviors that destroy the marine ecological function will be effectively restrained.

Firstly, MECRL should be identified. Based on data collection and combined with the distribution of important ecological function areas, ecologically sensitive areas and ecologically fragile areas throughout the country, importance assessment of marine ecological function should be carried out. Important estuaries, important 
coastal wetlands, islands under special protection, marine conservation areas, natural landscapes and historical and cultural relics, concentrated distribution areas of rare and endangered species, important fisheries areas, important coastal tourism areas, important sandy shorelines, protected sea areas of sand sources, mangroves, coral reefs and seaweeds and other extremely important areas should be identified.

Secondly, the special scale of MECRL should be determined. From the perspective of ecological protection, the greater the area, the better the protection effect will be. However, the larger the area, the greater the pressure will be on local economic development and financial transfer payment. At present, the delineation plans of MECRL have been released by coastal provinces and cities, mainly relying on the relevant technical specification documents, fully considering the management requirements and the current situation in different marine environmental resources, from the perspective of operability and practicability for MECRL. For some specific areas, it is necessary to analyze and delineate them according to the specific circumstances. At the same time, the coordination analysis with national and provincial marine function zoning, development strategic planning of coastal areas, marine economy development planning and other relevant national strategic planning should be done well, so as to identify the conflict areas that do not affect the development and utilization of ecological functions, and finally determine the scope.

Thirdly, the zoning management control measures should be developed.

Due to the particularity of ocean space, MECRL is different from other red line and is under differentiated control measures. Through spatial management constraints on the use of the sea, The utilization of marine resources that has an impact on the MECRL is prohibited, and gradually improve the ecological capacity of the marine resources and environment. According to different types of MECRL, differentiated control measures should be implemented from two aspects of general management requirements and detailed utilization control requirements, and the MECRL should be managed by its delineation and classification, and protected by the importance of the level. In principle, human activities are prohibited in the core areas and buffer zones of marine protection areas within MECRL. In other areas, productive construction activities and other activities that have an impact on protected objects are strictly prohibited. At the same time, special management measures can also be formulated for MECRL that has special requirements for certain periods of time.

\section{Practice of MECRL Delineation}

In July 2012, China launched the work of delineating Bohai Sea MECRL, which is the first time that China has applied ecological conservation red line to the ocean. At the end of December 2013, Shandong provincial government issued the Delineation Plan for the Bohai marine ecological conservation redline Area of Shandong Province, which is valid from 2013 to 2020 . The MECRL area is delineated 6534.42 square kilometers from the total 16313.9 square kilometers of sea area, making it the first province to implement the MECRL system in Bohai Sea in China. By July 2014, the delineation of the MECRL in Bohai Sea had been completed, including Hebei province, Tianjin city, the Bohai management areas of Shandong province and Liaoning province, and preliminary results showed good results. A total of 156 areas have been delineated under the Bohai Sea MECRL, effectively protecting more than 800 kilometers of natural shoreline, marine conservation areas, important estuaries and wetlands, and important fisheries areas, covering an area of more than 14,000 square kilometers. It will provide important technical support for the implementation of the strictest environmental protection policy, the establishment of MECRL system, and the promotion of marine ecological civilization in Bohai Sea.

The practice and application of MECRL delineation in Bohai Sea have been conducted on a trial basis and achieved good results, laying a good foundation for the comprehensive promotion of the MECRL delineation in China and the establishment of MECRL system. Since June 2014, China has been working on the national MECRL delineation. By the end of 2016, China had basically completed the delineation of MECRL in 11 coastal provinces and cities. By the end of 2017, MECRL had been issued and implemented. MECRL has been accounted for about 30 percent of the total coastal areas under management.

After the MECRL was delineated, its work shifted to strict compliance. China has implemented strict control measures in MECRL. Firstly, regular ecological monitoring and evaluation have been carried out. Through monitoring and evaluation, the ecological conditions of the protected targets within the MECRL can be found out, so as to give early warning in case of continuous ecological decline; Secondly, the key habitats and damaged ecosystems within the MECRL should be protected and restored, so as to improve their ecological services and restore the health and stability of the ecosystem. Thirdly, MECRL has been applied to Marine administrative licensing and administrative law enforcement, implement the strictest space access system, strictly control the access to the sea for projects, strictly protect and manage the use of coastline, and strictly punish human activities within the MECRL that violate the control measures. Fourthly, enhance red line quality performance appraisal, and carry out quality accountability for those who violate the control requirements, break the red line and cause ecological damage to the red line. Through the above measures, it will ensure that the MECRL is well guarded and managed.

\section{6 subtotal}

MECRL delineation method is generally operable and practical, but the difficulty lies in how to determine the boundaries of different classification scientifically and reasonably. There is no denying that due to the regional differences and the limitations of human cognitive level, in MECRL on the delineation of boundary, this method 
has certain limitations, such as important estuaries, important fisheries areas, sand protection areas can only be determined qualitatively with a delineation principle, which should be determined after specific analysis based on the practical situation. MECRL area delineated is not static, but a process of dynamic adjustment. With the improvement of cognitive level, the state of ecological restoration, resource and environment capacity in MECEL area, the delineation method will be improved and perfected on the basis of continuous practice.

MECRL, as an important component of the pattern of space development and protection, is the core element and mandatory content of space planning, and also an important basis for the unified implementation of space use control and marine ecological protection and restoration. At present, China is further optimizing the ecological protection red line, including MECRL. China's ecological red line will further optimize the spatial distribution pattern of MECRL based on the principle of "delimiting as much as is necessary and ensuring as much as is necessary" on the basis of identifying gaps and coordinating conflicts between marine protection and utilization

\section{Acknowledgement}

In the process of writing this article, we got the guidance and help from my colleagues, and we would like to express our deep thanks to them.

Thanks for the support of China National Offshore Oil Corporation (CNOOC) Marine Environment and Ecological Protection Public Welfare Foundation.

Fund name: Study on the coordination of spatial layout of Marine energy (wind power, oil and gas) development and utilization.

Fund number: CF-MEEC/TR/2020-05.

\section{References}

1. Li S J, Yang X, Wang J K. Study on policy frame of marine ecological protection red line. Marine Environmental Science, 2016, 35(2): 306-310.

2. Lin Y, Fan J F, Wen Q, Liu S X, Li B Y. Primary exploration of ecological theories and technologies for delineation of ecological redline zones. Acta Ecologica Sinica, 2016, 36(5): 1244-1252.

3. Huang W, Zeng J N, Chen Q Z, Du P, Tang Y B, Yang H. Preliminary research on the zoning method of the marine ecological redline: a case study of Hainan Province. Acta Ecologica Sinica, 2016, 36(1): 268-276.

4. $\mathrm{Hu} \mathrm{B}$, Chen $\mathrm{Y}$. The development of the marine eco-redline to the China's marine eco-security legal system. Chinese Journal of Maritime Law, 2018, 29(4): 94-101.

5. Liu S X, Wang Y, Wang R R, Yan J S, Fan J F, Wen Q. Study on the delimitation method of the overloading area of marine resources and environment in the red line area. Marine Science Bulletin, 2017, 36(5): 497-503.
6. Chen G L, Hu W J, Chen B, Ma Z Y, Liao J J. Marine spatial planning using in marine ecological red line zoning - - a case study of dongshan county. Journal of Applied Oceanography, 2017, 36(1): 6-15.

7. XU Y, LIANG B, BAO C G, LAN D D, YU C Y, MA M H. Research on the index system and the technical methods of ecological red line division for the Bohai Sea. Marine Science Bulletin, 2013, 32(4): 361-367. 